\title{
Behavioral treatment of insomnia: a proposal for a stepped-care approach to promote public health
}

REVIEW

\author{
Laurin J Mack \\ Bruce D Rybarczyk \\ Clinical Psychology Program, \\ Department of Psychology, \\ Virginia Commonwealth \\ University, Richmond, VA, USA
}

This article was published in the following Dove Press journal:

Nature and Science of Sleep

25 July $201 \mathrm{I}$

Number of times this article has been viewed

\begin{abstract}
Chronic insomnia is a highly prevalent condition that has psychological and medical consequences for those who suffer from it and financial consequences for both the individual and society. In spite of the fact that nonpharmacologic treatment methods have been developed and shown to be as or more effective than medication for chronic insomnia, these methods remain greatly underutilized due to an absence of properly trained therapists and a general failure in dissemination. A stepped-care model implemented in a primary-care setting offers a public health solution to the problem of treatment accessibility and delivery of behavioral treatments for insomnia. Such a model would provide graduated levels of cognitive behavioral intervention, with corresponding increases in intensity and cost, including self-help, manualized group treatment, brief individual treatment, and finally, individualized behavioral treatment provided by a specialist. To provide such a systematic approach, future research would need to confirm several aspects of the model, and a cadre of professionals would need to be trained to administer manualized care in both group and individualized formats.
\end{abstract}

Keywords: cognitive behavioral therapy, chronic insomnia, stepped care, primary care

\section{Introduction}

Insomnia is a general clinical term that refers to difficulty initiating or maintaining sleep. Insomnia may be the only presenting symptom (primary insomnia) or it can co-occur with other physical or mental disorders (comorbid insomnia). Both primary and comorbid insomnia can be acute (duration less than 30 days) or chronic. Chronic insomnia is defined as difficulty falling or staying asleep on a daily or nearly daily basis for at least 1 month and causes significant distress or has a negative impact on important areas of functioning. ${ }^{1}$

In the insomnia research literature, the diathesis stress model is the predominant theoretical framework for the development and treatment of chronic insomnia. ${ }^{2}$ This model posits that predisposing factors such as trait hyperarousal in combination with precipitating factors such as a stressful event can lead to short-term difficulty falling asleep or staying asleep. ${ }^{3}$ Chronic insomnia develops when the acute sleep disturbance is maintained by perpetuating behavioral and cognitive factors, even after the initial precipitating event has passed.

This cognitive behavioral understanding of the genesis of chronic insomnia also provides a theoretical framework for the treatment of insomnia. Effective treatment must address the cognitive and behavioral mechanisms that maintain insomnia. ${ }^{2}$ Therefore, the current best practices of nonpharmacological treatments for insomnia target both 
dysfunctional attitudes and beliefs about sleep ${ }^{4}$ and maladaptive behaviors (increased time in bed) that maintain abnormal sleep patterns. ${ }^{5}$

Insomnia affects individuals of all ages. Over 30\% of the US population reports symptoms of insomnia, and $6 \%$ meet the diagnostic criteria for chronic insomnia. ${ }^{6}$ Insomnia is more common among women, shift workers, individuals with psychiatric and medical disorders, and it is especially common among adults over the age of 55.,7

Insomnia places a significant financial burden on the individual and society. Individuals who complain of sleep disturbance are more likely to use the health care system. ${ }^{8,9}$ Walsh and Engelhardt ${ }^{10}$ estimate that the total direct US domestic cost of insomnia was US\$13.9 billion in 1995, which resulted from substances purchased to treat the insomnia and higher health care utilization. More liberal estimations that take into account decreased workplace productivity peg the total direct and indirect cost of insomnia for the US at US\$92.5-\$107.5 billion annually. ${ }^{11}$

The burden of insomnia is much more than financial. Insomnia has a negative impact on the psychological and physical health of those who suffer from it. Insomnia is correlated with self-report of depression, ${ }^{8,12-14}$ fatigue, ${ }^{9}$ and overall quality of life. ${ }^{12}$ Chronic insomnia has also been associated with impaired cognitive function, accident risk, and absenteeism. ${ }^{15,16}$ Further, recent research suggests that untreated insomnia may have a role in the onset and progression of conditions such as depression, including suicide risk, hypertension, cardiovascular disease, and diabetes ${ }^{17}$ Finally, daytime symptoms of chronic disease may be exacerbated by co-occurring sleep issues. ${ }^{18}$

Traditionally, insomnia was categorized as "secondary insomnia" if it was determined to be a consequence of another primary medical or psychiatric disorder. ${ }^{19}$ However, due to the difficulty in determining whether coexisting conditions precede and/or exacerbate the insomnia, a 2005 State-of-the-Science Conference ${ }^{20}$ recommended that the term "comorbid insomnia" be used in place of "secondary insomnia" when other conditions coexist. Among older adults, comorbid insomnia may account for as much as $70 \%$ of insomnia. ${ }^{21}$

\section{Effective treatments for insomnia}

Most people who seek treatment for acute or chronic insomnia discuss it with their primary-care providers ${ }^{22}$ and are usually prescribed sleep medications and/or sometimes referred to a sleep specialist for further evaluation. ${ }^{23,24}$ Medications that are commonly prescribed to treat insomnia include benzodiazepines (triazolam), nonbenzodiazepines (zolpidem), antihistamines (Benadryl ${ }^{\circledR}$, McNEIL-PPC Inc, Fort Washington, PA) antidepressants (trazodone), or atypical antipsychotics (Seroquel ${ }^{\circledR}$ or quetiapine). There is a wide consensus that standard hypnotic medications are an effective first-line treatment for acute insomnia, lasting less than 1 month, ${ }^{25,26}$ but more research is necessary to affirm the efficacy and safety of longer-term medication use. ${ }^{25,26}$ In fact, the US Food and Drug Administration has only approved one hypnotic medication, eszopiclone, for long-term use. Despite the absence of evidence regarding the efficacy and safety of long-term hypnotic use, it is quite common for individuals to continue to use them for months or years. ${ }^{27}$ Logically, although no such survey studies have been conducted, it would appear that a significant portion of these users are obtaining benefits from long-term use of the medication. However, it is unknown what portion of these individuals maintains their use of hypnotics because they experience rebound insomnia when they attempt to discontinue use and erroneously conclude that the medications are providing some benefit.

Although a number of potential short-term side effects of hypnotic medications have been reported, such as disrupted transitioning through sleep stages, sedation, amnesia, psychomotor and cognitive impairments, ${ }^{25,28,29}$ more research is necessary to determine the safety and side effects of longterm hypnotic use. ${ }^{26}$ Additionally, although hypnotic medications are discouraged for long-term use in older adults due to adverse side effects such as psychomotor and cognitive slowing, daytime fatigue and increased risk for falls, they are routinely used by this segment of the population. ${ }^{30}$ Hence, research should focus on consequences of long-term use in older adults in particular.

Even less is known about the efficacy and safety of the off-label use of antidepressants and antipsychotics, even though several are widely prescribed under the presumption that they are safer than standard hypnotics for long-term use. A recent review indicates trazodone, an antidepressant with significant sedating effects, is one of the most frequently prescribed medications for chronic insomnia, despite insufficient evidence supporting its long-term efficacy and possible cardiac side effects. ${ }^{31}$

Nonpharmacological interventions for insomnia include behavioral interventions such as stimulus control, sleep restriction, relaxation training, and sleep hygiene. ${ }^{7}$ Stimulus control ${ }^{32}$ is a behavioral technique used to help patients learn to associate bed with sleep. It requires patients who cannot fall asleep within 15 minutes to get out of bed, go to another 
dimly lit room, and engage in a nonstimulating task. Patients are allowed to return to the bed only when they feel sleepy again, and bed is to be used for sleep or sex only. Another behavioral technique is sleep restriction, ${ }^{33}$ which entails setting a strict schedule of bedtimes and arising times to decrease time spent awake in bed. Relaxation training is an attempt to decrease anxiety and reduce cognitive and physiological arousal at bedtime. It entails techniques such as deep breathing, positive imagery, and progressive muscle relaxation. Sleep hygiene education is an attempt to inform patients about optimal sleep conditions. It involves measures to improve the overall sleep environment such as having an appropriate bedroom temperature and reducing ambient noise in the bedroom. Cognitive restructuring, first introduced by Morin, ${ }^{34}$ is an attempt to challenge and modify unrealistic beliefs and irrational fears about one's sleep patterns. This involves educating patients about normal and abnormal sleep, identifying and addressing maladaptive beliefs, and then replacing them with more adaptive ones. ${ }^{35}$ Individually these interventions can be used to improve sleep outcomes. . $33,36,37^{-3}$

Cognitive behavioral therapy for insomnia (CBT-I) is a multicomponent treatment that is comprised of the individual behavioral treatments discussed above plus cognitive restructuring. ${ }^{38} \mathrm{CBT}-\mathrm{I}$ has demonstrated effect sizes that are equal to or greater than most single component intervention studies. ${ }^{39}$ CBT-I is usually delivered by a therapist in four to eight, 50-90-minute weekly sessions. ${ }^{34,40}$

Dozens of randomized clinical trials of CBT-I have demonstrated clear improvements in sleep outcome variables, with between $70 \%$ and $80 \%$ of insomnia patients typically reporting benefits from treatment when intent-to-treat analyses are employed..$^{24,41}$ To date, nine systematic reviews or metaanalyses of CBT-I exist in the insomnia treatment literature, indicating moderate-to-large effect sizes for reductions in sleep latency and wake time after sleep onset along with increases in sleep efficiency. ${ }^{42}$ Approximately $75 \%$ of these effects are maintained at long-term follow-up, measured up to 2 years after active treatment. ${ }^{26}$ Limitations on the findings include smaller effects for objective measures relative to self-report and only small effects for increased total sleep time, although both of these limitations are also found in the randomized clinical trials (RCT) for hypnotics. CBT-I research follows guidelines of reporting dropouts and usually employs intent-to-treat analyses, as is required for pharmaceutical trials. The main weakness within the CBT-I RCTs relative to those conducted for medications is the larger sample sizes and the fact that few behavioral studies have created placebo control groups, though there are some notable exceptions. ${ }^{43}$
These reviews also show there are no differences in therapeutic response between younger and older adults or as a function of the type of insomnia (sleep onset vs sleep maintenance type), duration of insomnia, or severity of insomnia. ${ }^{44}$ Additionally, a recent review by Smith, Huang, and Manber ${ }^{38}$ concluded that CBT-I is an effective treatment for those with chronic insomnia who suffer from a wide range of comorbid psychiatric and medical conditions. Thus, CBT-I has proven to be an efficacious treatment for all forms of chronic insomnia regardless of what may have initially contributed to the onset of insomnia.

According to a recent review which summarizes and compares effect sizes from pharmacological and nonpharmacological treatment studies for chronic insomnia, CBT-I and pharmacotherapy have comparable outcomes after 4-8 weeks of treatment, but the therapeutic benefits of CBT-I are more likely to continue after treatment is terminated. ${ }^{26}$ Further, there have been five studies that have randomized participants into CBT-I or pharmacotherapy conditions, ${ }^{41,45,46}$ directly comparing both short-term and long-term benefits (see Table 1). As noted in Table 1, these studies show equal or better effects for CBT-I at posttreatment but consistently show significantly greater effects for CBT-I at follow-up. These studies also report comparable dropout rates across conditions. In addition to the long-term benefits of CBT-I, participants surveyed in a study by Morin and colleagues ${ }^{47}$ indicated that they preferred behavioral treatment over pharmacotherapy. Additionally, results showed that participants expected that behavioral treatment for insomnia would have better long-term effectiveness and fewer side effects than pharmacotherapy.

Unfortunately, despite the negative consequences of insomnia and the demonstrable efficacy of CBT-I, a majority of those suffering from chronic insomnia go untreated..$^{9,48}$ Most people who seek treatment for insomnia discuss it with their primary-care providers, who in turn typically prescribe sleep medication ${ }^{22}$ rather than nonpharmacological treatments. ${ }^{50}$ This is likely due to physicians' lack of familiarity with viable behavioral alternatives ${ }^{22}$ and that medication is perceived as a less expensive and an easier treatment method than behavioral treatments. ${ }^{22,49}$ Although the true cost of medication and behavioral treatments is an area that requires further research, ${ }^{26}$ one comparative meta-analysis of pharmacotherapy and CBT-I for the treatment of chronic insomnia compared the costs of CBT-I and Ambien. ${ }^{51}$ The results of a cost comparison showed that pharmacotherapy may have fewer direct costs in the short-term but is significantly more expensive that CBT-I in the long-term.

The reliance on sleep medications in primary care may also reflect the relative inaccessibility of CBT-I. ${ }^{49}$ There are 
Table I Summary of randomized studies directly comparing CBT to hypnotic medications

\begin{tabular}{|c|c|c|c|c|c|}
\hline Study & $\begin{array}{l}\text { Treatment } \\
\text { conditions }^{\mathrm{a}}\end{array}$ & $\mathbf{N}$, mean age & Results at posttreatment & Follow-up period & Results at follow-up \\
\hline $\begin{array}{l}\text { McClusky } \\
\text { et al }\end{array}$ & CBT vs TZ & $\begin{array}{l}\mathrm{N}=30, \text { mean } \\
\text { age }=32\end{array}$ & $\begin{array}{l}\text { Self-report: CBT }=\text { TZ for improvements } \\
\text { in SL and TST }\end{array}$ & 9 weeks & $\begin{array}{l}\text { All participants maintained } \\
\text { gains for SL and TST, CBT > } \\
\text { TZ for improvements in SL } \\
\text { CBT = TZ for TST }\end{array}$ \\
\hline $\begin{array}{l}\text { Morin } \\
\text { et } \mathrm{al}^{41}\end{array}$ & $\begin{array}{l}\text { CBT vs TM } \\
\text { vs PL }\end{array}$ & $\begin{array}{l}\mathrm{N}=78, \text { mean } \\
\text { age }=65\end{array}$ & $\begin{array}{l}\text { Self-report: CBT, TM > PL for } \\
\text { improvements in TWT, SE, WASO } \\
\text { PSG: CBT, TM > PL for improvements } \\
\text { in WASO }\end{array}$ & 24 months & $\begin{array}{l}\text { Only CBT participants } \\
\text { maintained sleep gains for } \\
\text { TWT, WASO, SE }\end{array}$ \\
\hline $\begin{array}{l}\text { Jacobs } \\
\text { et } \mathrm{al}^{46}\end{array}$ & $\begin{array}{l}\text { CBT vs } Z P \\
\text { vs PL }\end{array}$ & $\begin{array}{l}\mathrm{N}=63, \text { mean } \\
\text { age }=47\end{array}$ & $\begin{array}{l}\text { Self-report: CBT > ZP for improvements } \\
\text { in SL, SE } \\
C B T=Z P \text { for improvements in TST }\end{array}$ & 12 months & $\begin{array}{l}\text { Only CBT had f/u. All CBT } \\
\text { gains maintained }\end{array}$ \\
\hline $\begin{array}{l}\text { Sivertsen } \\
\text { et } \mathrm{al}^{45}\end{array}$ & $\begin{array}{l}\text { CBT vs } Z P \\
\text { vs PL }\end{array}$ & $\begin{array}{l}\mathrm{N}=46, \text { mean } \\
\text { age }=62\end{array}$ & $\begin{array}{l}\text { Self-report: CBT = ZP for improvements } \\
\text { in TWT and TST } \\
\text { PSG: CBT > ZP, PL for improvements } \\
\text { in TWT CBT > PL for SE }\end{array}$ & 6 months & $\begin{array}{l}\text { Self-report: CBT > ZP for } \\
\text { improvements in TWT } \\
\text { PSG: CBT > ZP for } \\
\text { improvements in TWT, SE }\end{array}$ \\
\hline Wu et al ${ }^{106}$ & $\begin{array}{l}\text { CBT vs TM } \\
\text { vs PL }\end{array}$ & $\begin{array}{l}\mathrm{N}=7 \mathrm{I}, \text { mean } \\
\text { age } 38\end{array}$ & $\begin{array}{l}\text { Self-report and PSG: TM, CBT > PL } \\
\text { for improvements in SL, SE, TST } \\
\text { TM }>\text { CBT for improvements in SL, SE, TST }\end{array}$ & 8 months & $\begin{array}{l}\text { Self-report and PSG: CBT > } \\
\text { TM for improvements in SL, } \\
\text { SE, TST }\end{array}$ \\
\hline
\end{tabular}

Notes: ${ }^{\mathrm{B}}$ Because the purpose of this table was to show results of a direct comparison of CBT to hypnotics in a randomized study, treatment groups that combined CBT and hypnotic medication were not reported.

Abbreviations: CBT, cognitive behavioral therapy; PL, placebo; PSG, polysomnography; SL, sleep latency; SE, sleep efficiency; TM, temazepam; TST, total sleep time; TWT, total wake time; TZ, triazolam; WASO, wake after sleep onset; ZP, zoplicone.

simply not enough clinicians trained in the delivery of behavioral sleep medicine. ${ }^{52}$ Even if behavioral sleep medicine resources were not limited, older patients and patients with chronic health issues would still face issues of accessibility because of mobility and financial restrictions that may limit their ability to visit a sleep clinic for the required weekly sessions. ${ }^{53,54}$ There is a critical need to make CBT-I more accessible and affordable to the general public.

For the past two decades, the focus of behavioral sleep medicine research has been on developing and testing an effective treatment for insomnia. Now that CBT-I has been established as the gold standard for treating chronic insomnia, there is a critical need to make this intervention more easily accessible and affordable to the general public. CBT-I is one of psychology's "best kept secrets" 55 because there are not enough professionals trained in its delivery to meet the demands of those suffering from insomnia. In addition, the call of those advocating this effective and long-lasting treatment is often drowned out by the booming voice of pharmaceutical advertisements. ${ }^{55}$ CBT-I should be considered a primary treatment option for chronic insomnia and is even reimbursed by most behavioral health insurance plans, but instead it remains largely unheard of as far as mainstream insomnia treatment goes. Thus, the great challenge of CBT-I is to improve its delivery system. ${ }^{42}$ In order to address the enormous treatment need, simply increasing numbers of CBT-I therapists will not suffice. New models of CBT-I delivery must be developed. ${ }^{42}$

\section{Research on behavioral treatments for insomnia in primary care settings}

There are a small but growing number of studies which have evaluated specific behavioral treatments for insomnia in primary-care settings. These studies provide preliminary evidence for the feasibility of integrating CBT-I treatment into primary-care settings. Two early research studies used stimulus control as a single component behavioral treatment in their research design, ${ }^{56,57}$ with one study using it as an adjunct to "as needed" pharmacotherapy ${ }^{57}$ Both of these studies provided preliminary evidence that brief behavioral interventions can be implemented in primary-care settings by a physician. However, more recent research has moved away from testing interventions that are delivered by a physician, likely in recognition of the time constraints faced by a physician for patient visits.

Espie and colleagues ${ }^{58,59}$ conducted two important studies that evaluated the effectiveness, feasibility, and cost-efficiency of CBT-I delivered by nurses in primary-care settings. In the first effectiveness study, ${ }^{59}$ potential participants were recruited from primary-care practices in Ayrshire, Scotland. 
Participants were randomly assigned to a CBT-I condition or a self-monitoring wait-list control group. Participants in the treatment group attended six 50-minute group sessions led by nurses trained to deliver manualized CBT-I. Of the 161 participants who were enrolled in the study, 139 participants completed the protocol and 109 participants provided 12-month follow-up assessment data. Participants in the treatment group experienced substantially reduced sleep onset latency and wake after sleep onset (about 30 minutes per night) compared with the control group. These improvements were maintained at 12-month follow-up. Another important study outcome was that $84 \%$ of participants who used hypnotics at baseline remained drug-free at follow-up. ${ }^{59}$

A second study by Espie and colleagues ${ }^{58}$ built on the 2001 effectiveness study by randomizing participants to either the CBT-I or treatment-as-usual group. For this study, 201 adults who met criteria for chronic insomnia were recruited from primary-care settings in Scotland. Those in the CBT-I group participated in five 1-hour group sessions led by primary care nurses who were trained to deliver manualized CBT-I for this study. Those in the control group received usual care from general practitioners, meaning that their physicians were free to prescribe, maintain, or discontinue prescriptions. Participants in the treatment group were also permitted to continue treatment as usual with their regular doctor in addition to participating in the group CBT-I treatment. Those in the CBT-I group experienced significant improvements in self-reported measures of sleep, which included sleep latency and time awake after sleep onset, and 9\% improvement in sleep efficiency. Participants in the treatment group also showed improvements in health-related quality-of-life. Selfreported sleep improvements proved to be partially durable at 6-month follow-up. Participants in the treatment-as-usual group showed no improvement in sleep, according to both self-report and objective (actigraphy) measures.

These studies conducted by Espie and colleagues have significant implications for the proposed stepped-care model of insomnia treatment because they provide evidence that health professionals other than behavioral sleep specialists can effectively deliver CBT-I. The treatment effects in Espie and colleagues' ${ }^{\prime 59}$ study are equivalent to studies which use trained clinical psychologists to deliver CBT-I. ${ }^{39,41}$ Primarycare nurses are in the ideal position to lead such groups because they are already embedded in the primary health care system. ${ }^{59}$ Further, the samples selected for both studies were representative of "real world" patients who seek treatment for insomnia in primary-care settings due to the fact that both studies allowed participation by individuals who had severe chronic insomnia, had comorbid mental or physical health problems, and/or used sleep medications. The studies of Espie and colleagues ${ }^{58,59}$ provide evidence to support the effectiveness of CBT-I as well as the feasibility of implementing a manualized, nurse-administered small group CBT-I intervention in a primary-care setting.

Two additional studies evaluated the effectiveness of abbreviated CBT-I treatment in primary-care settings. ${ }^{22,60}$ Edinger and Sampson ${ }^{22}$ conducted a study in which 20 primary-care patients from the Durham Veterans Administration Medical Center were randomly assigned to either a two-session CBT-I protocol specifically designed to be implemented in primary care or a contact control group which involved basic psycho-education about sleep and sleep hygiene suggestions. The study results indicated that the abbreviated CBT-I treatment was more effective than the control group on outcome measures which included global insomnia symptoms and dysfunctional attitudes about sleep. The authors compared the results of the abbreviated CBT-I group to the results of a previous RCT that evaluated a six-session CBT-I protocol. ${ }^{61}$ The treatments proved to be comparable despite the differences in study samples and methodology.

A recently conducted uncontrolled case series study evaluated the effectiveness of a brief CBT-I intervention that was administered to 29 adults in a family-care setting. ${ }^{60}$ Unlike the Edinger and Sampson ${ }^{22}$ study described above, participants who used sleep medication or had comorbid physical or mental health issues were not excluded from this study. Three clinical psychologists with specialized primary-care training delivered the behavioral intervention. Treatment sessions lasted between 10 and 25 minutes, during which patients were provided with education and behavioral recommendations to address their individual sleep problems. Each participant was also given a self-help book for insomnia, Say Good Night to Insomnia, ${ }^{62}$ at the end of the treatment period to support the information provided by the psychologist. Participants scheduled treatment sessions at their convenience in accordance with the usual primary-care procedure. Therefore, some sessions were separated by more than 2 weeks. Treatment sessions were discontinued when participant's sleep efficiency reached $85 \%$ or when individual goals for sleep improvement were met. Study participants showed significant improvement in standardized measures of sleep quality and quantity at post-treatment as well as improved sleep satisfaction and daytime functioning. 
These studies were the first to test an abbreviated individually administered CBT-I intervention in a primary-care setting. The results of both studies provide preliminary support that a brief CBT-I treatment coupled with bibliotherapy delivered by psychologists is an effective treatment for insomnia in primary-care settings. ${ }^{22,60}$ The success of the abbreviated treatment protocols implies that office resources as well as therapist and patient time could be conserved by reducing the number of sessions required for successful treatment. In fast-paced primary-care settings, it may not be possible to schedule more than a few appointments with a health care provider who is responsible for the care of hundreds of other patients. In this regard, the flexible scheduling of the therapy sessions used in both studies ${ }^{22,60}$ better resembles the day-today administration of a primary-care practice.

\section{Stepped care and insomnia}

The problem of treatment delivery and accessibility is not specific to the treatment of insomnia. As CBT has gained increased recognition as an effective treatment for depression, anxiety, and an expanding number of other behavioral and psychological disorders, the supply of CBT therapists has fallen far short of the demand for them. ${ }^{63}$ An epidemiological study by Kessler and colleagues ${ }^{64}$ showed that many people with psychological disorders have never received treatment, much less empirically supported treatment delivered by a trained professional. The health care community must figure out how to utilize limited resources to deliver effective interventions to as many people as possible. ${ }^{65}$ A stepped-care approach to treatment delivery represents one attempt to maximize efficiency of resource allocation of evidence-based treatments. ${ }^{65,66}$ Stepped-care models have already been applied to a number of behavioral health and psychological problems such as depression, ${ }^{66,67}$ generalized anxiety disorder, ${ }^{68}$ childhood anxiety, ${ }^{69}$ eating disorders, ${ }^{70}$ substance abuse, ${ }^{71}$ and obsessive compulsive disorder. ${ }^{72}$ Furthermore, the United Kingdom's National Institute for Health and Clinical Excellence has developed elaborate stepped-care plans that have been implemented across the health care system for depression and anxiety. ${ }^{73,74}$

Stepped care is a treatment delivery model which is based on the premise that interventions should vary in type and/ or intensity, especially in health care systems with limited resources. ${ }^{65}$ According to the stepped-care model, lower cost interventions are attempted first while more expensive and intensive treatments are reserved for those who do not respond to less intensive interventions. ${ }^{65}$ An additional purpose of a stepped-care approach to treatment dissemination is to improve treatment efficiency by standardizing systems and procedures. ${ }^{66,75}$

A stepped-care model can be thought of as a pyramid. Less intensive treatments are used to treat greater numbers of patients at the bottom of the pyramid, while fewer patients are treated with progressively more intense treatments at the top of the pyramid..$^{42}$ The entry level of a stepped-care model should be the simplest, most cost-effective and least intrusive intervention. The succeeding steps provide incrementally more intensive (and therefore more expensive) treatment. ${ }^{66}$ If a patient does not fully respond to the initial level of treatment, they are progressively "stepped up" to more intensive, intrusive, and expensive treatments until their therapeutic goals are met. ${ }^{76}$ A step up can mean changing to a more intensive treatment regime (bibliotherapy to group therapy) or providing an additional mode of treatment (bibliotherapy plus pharmacotherapy). ${ }^{77}$

As noted by Espie, ${ }^{42}$ insomnia is an ideal disorder to be treated using a stepped-care model because it is widespread and there is a shortage of skilled professionals qualified to deliver CBT-I. Also, the varying severity and complexity of insomnia across individuals warrants different treatment levels. Finally, the stepped-care approach is appropriate for insomnia because although it is a chronic disorder which can be associated with long-term risks to health, it rarely has acute or immediately dangerous consequences. Therefore, even if patients do not respond to a lower level of treatment before they are referred to the next level of more intensive treatment, most likely there will not be immediate dire consequences. ${ }^{42}$ CBT-I is also a suitable treatment to be used in a stepped-care model because it can be delivered in a variety of different forms (therapist-led individual therapy, group therapy, selfhelp), ${ }^{42}$ and it allows for dosing to be adjusted by means of increasing the number of sessions delivered and varying the number of components of the treatment offered (cognitive restructuring, sleep restriction). The qualifications of the therapist can also vary (nurse, $\mathrm{PhD}$, or MA level counselor, trained sleep specialist). ${ }^{42}$

In an effort to address the problems of CBT-I accessibility and treatment dissemination, a stepped-care approach to insomnia treatment has been discussed and advocated by leaders in the behavioral sleep medicine field. ${ }^{42,55}$ Edinger and Carney ${ }^{78}$ proposed a stepped-care model for the delivery of CBT-I in which the first level of treatment involves efforts to increase public knowledge of insomnia and behavioral treatments through public education delivered via the media. The use of mass media as a method for disseminating public education about insomnia has garnered some research support. ${ }^{79}$ 
The second step would be self-help treatments delivered via a variety of proven modalities such as bibliotherapy ${ }^{80,81}$ or interactive internet programs. ${ }^{82-84}$ The third step in Edinger and Carney's model involves group CBT-I delivered by nonbehavioral medicine specialists (ie, nurses, social workers) trained to deliver manualized CBT-I. The fourth step would be individually administered CBT-I, led by psychologists trained in behavioral sleep medicine. The final step in Edinger and Carney's model is referral to specialized sleep centers for treatment by certified behavioral sleep medicine experts. ${ }^{78}$ Espie $^{42}$ proposed a stepped-care model for insomnia which largely resembled Edinger and Carney's ${ }^{78}$ model with a few exceptions. ${ }^{42}$ Instead of public education as the initial treatment step, the first step of Espie's model is self-administered CBT-I. The second step of Espie's model is group CBT-I delivered by trained nurses, ${ }^{58}$ followed by individual or group CBT-I, led by a graduate psychology student. The fourth step is individual CBT-I administered by a licensed clinical psychologist, and then finally, expert CBT-I delivered by a behavioral medicine sleep specialist.

Although Edinger ${ }^{78}$ and Espie ${ }^{42}$ have proposed conceptual models for a stepped-care approach for insomnia treatment and have started a discussion within the field of behavioral sleep medicine, there has yet to be an actual stepped-care model for insomnia implemented in a public health setting. Since most people who seek treatment for insomnia discuss it with their primary-care providers, ${ }^{22}$ a primary-care setting would be the ideal place to implement a stepped-care insomnia treatment model.

\section{Stepped care for the treatment of insomnia in primary care}

Low-cost evidence-based treatments offered as part of a stepped-care model implemented in primary care could benefit patients, health care providers, and insurance companies. The annual direct and indirect cost of mental health problems is greater than US\$148 billion. ${ }^{66,85}$ Since primary care is the first place that most people go to address medical and psychosocial health issues, ${ }^{86}$ the stepped-care model would be especially beneficial for primary care as it struggles to increase evidence-based treatment for mental health disorders. ${ }^{71}$

The prevalence of patients presenting with insomnia in primary care has been estimated in a variety of epidemiological studies to be from $10 \%$ to $37 \%$. From these studies, we know insomnia is widespread in primarycare populations and is associated with increased health care utilization, functional impairment, and symptoms of anxiety and depression. ${ }^{9,87,88}$ New clinical pathways are needed for the effective and efficient treatment of insomnia in primary care. Figure 1 illustrates a clinical pathway model proposed by the authors for treating insomnia in primarycare settings which incorporates both pharmacological and nonpharmacological treatments. Using this approach, patients who are diagnosed by their primary-care provider with acute or episodic insomnia would be offered appropriate pharmacotherapy in addition to a patient education booklet about the nature of insomnia, how acute insomnia develops into chronic insomnia as a result of behavioral factors, available treatments for insomnia, and healthy sleep practices. Those patients diagnosed with chronic insomnia, or who do not respond to pharmacotherapy for their previously diagnosed acute insomnia, would be referred to CBT-I.

To address the issues of CBT-I accessibility, the authors have built on the generic models of stepped care for insomnia discussed earlier in this paper, ${ }^{42,78}$ and propose a four-step treatment model tailored specifically for a primary-care setting, which is illustrated in Figure 2. The first of the four steps would be a 6-week minimal contact self-help CBT-I treatment program. With minimal contact self-help, the treatment rational is introduced by a health care provider, but the actual treatment is conducted primarily at home via self-help materials. ${ }^{89}$ The 6-week schedule would follow the standard sequence for CBT-I. ${ }^{34}$ Patients completing this step would be offered bibliotherapy ${ }^{80}$ or internet-based self-help treatments $^{82-84}$ depending on patient preference, computer access, and literacy. Two recent studies lend support to the efficacy of internet-based self-help CBT-1. A study by Ritterband and colleagues ${ }^{83}$ found that participants $(n=44)$ with primary insomnia who were randomly assigned to internet-based treatment showed significantly improved sleep compared with those in the wait-list control group. Similar results were found by Vincent and Lewycky ${ }^{84}$ in a Canadian study which tested an internet CBT-I intervention for participants $(n=118)$ with comorbid insomnia. Of particular note, the attrition rate of participants referred by physicians was more than double the attrition of those participants who were self-referred from the community. This high rate of attrition among physician-referred participants could have implications for stepped-care insomnia treatment in primary care and will be addressed later in this paper.

Patients who make significant improvements during the first step of treatment would discontinue treatment, while those who do not respond to self-help would step up to the second level of treatment: group CBT-I, led by nurses trained in manualized CBT-I. Treatment would consist of six 50-minute weekly CBT-I 

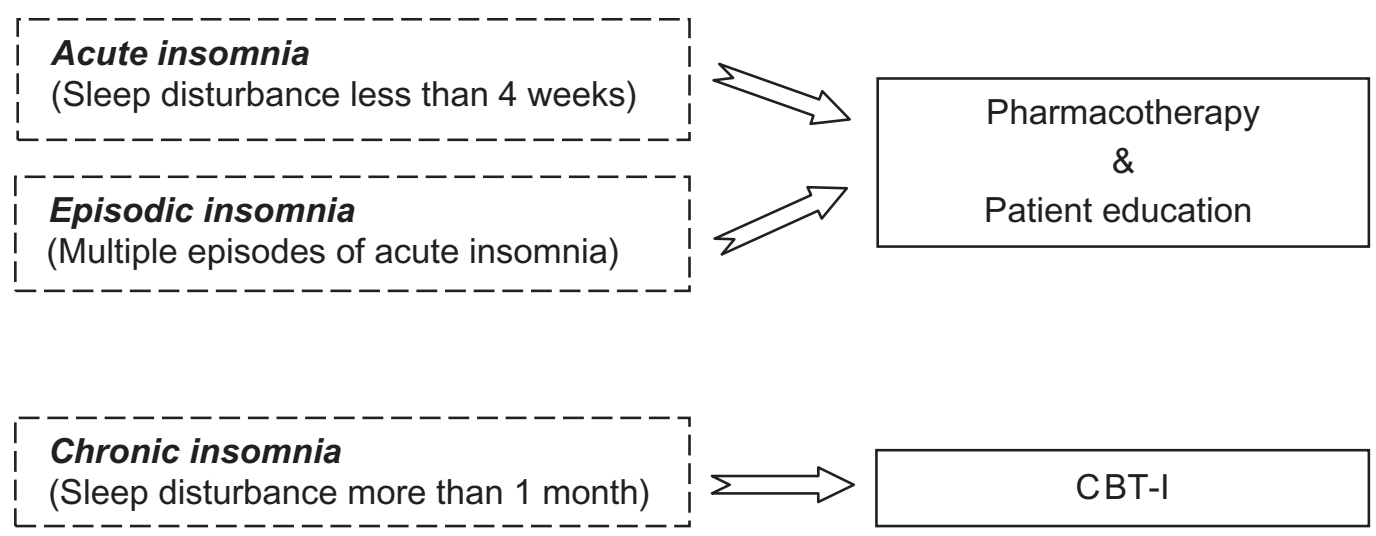

Figure I A proposed model for an insomnia clinical pathway in primary care. Abbreviation: CBT-I, cognitive behavioral therapy for insomnia.

group sessions.$^{59}$ The third step of the primary care stepped-care model would be brief individual treatment with a health care professional. The therapist for this step will depend on the staff options available with appropriate training in behavioral sleep medicine. This individually administered CBT-I intervention will be delivered in four, 50-minute biweekly sessions. Four biweekly sessions has been determined to be the optimal dosing for the individual CBT-I. ${ }^{40}$ If the patient's treatment goals have still not been met, they will move to the fourth step which is referral to a certified behavioral sleep medicine specialist for further evaluation in a sleep clinic.

In the proposed model, it is not necessary for patients to discontinue sleep medication usage if they choose to undergo CBT-I treatment. In fact, a recent study suggested that immediate posttreatment benefits from CBT-I may be enhanced modestly by adjunctive treatment with zolpidem. ${ }^{90}$ However, it was noted that 6-month treatment benefits were reduced when zolpidem use was continued after the initial acute treatment phase. $^{90}$

Patients will be not be referred to the stepped-care treatment if they are currently abusing prescription medications, illegal drugs, or alcohol, or meet diagnostic criteria for other sleep disorders (sleep apnea) based on screening questions or a home assessment method. Patients may also opt out of the stepped-care treatment and be referred directly to a sleep center for individualized treatment. Computerized

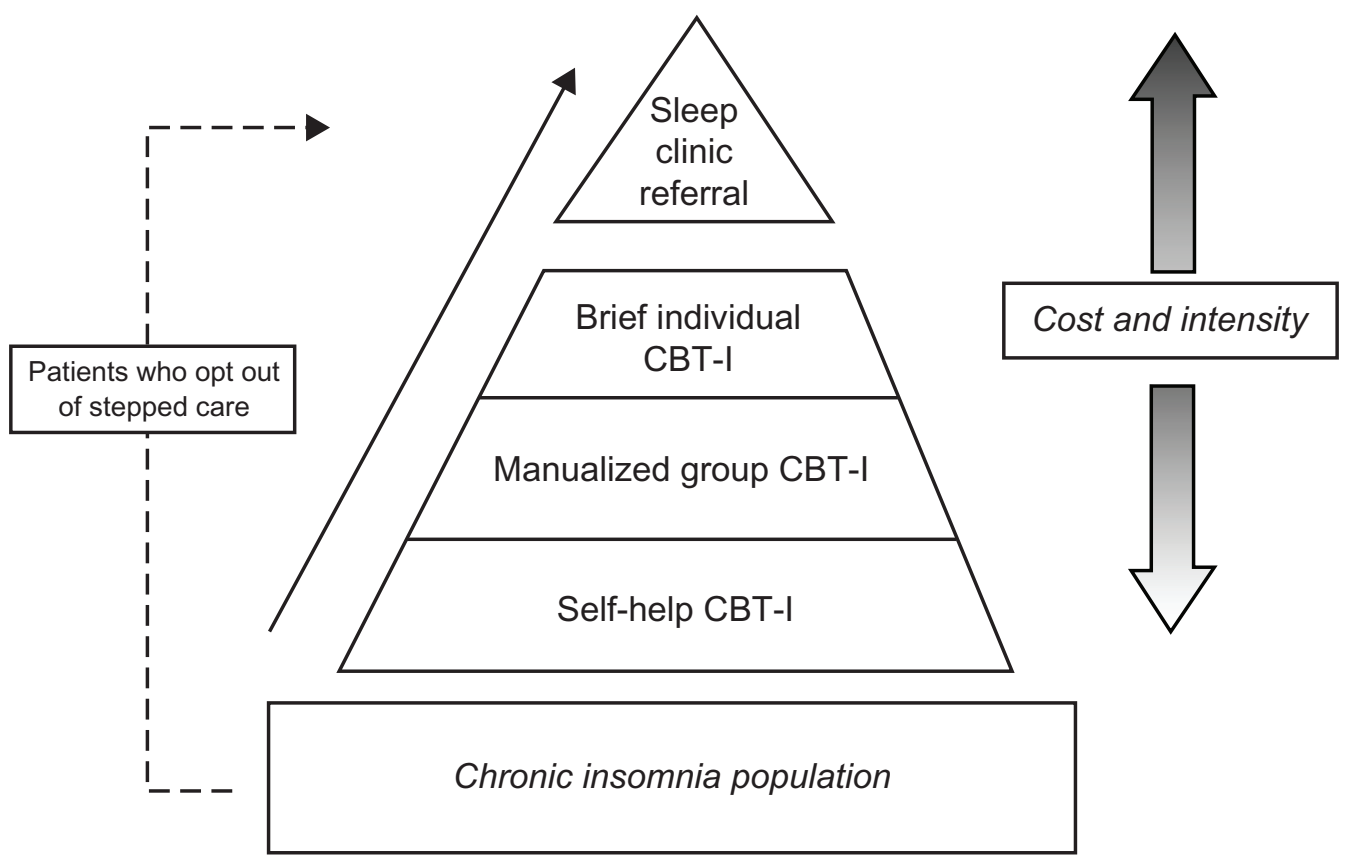

Figure $2 \mathrm{~A}$ model for stepped-care treatment for chronic insomnia in primary care indicating how patients might move through the cognitive-behavioral treatment levels. As treatments become progressively more individualized and intense, they also become more costly to the individual and the health care system.

Abbreviation: CBT-I, cognitive behavioral therapy for insomnia. 
monitoring systems designed to integrate with patients' medical records will track patient progress throughout the stepped-care model, which will be monitored by designated staff. Finally, with the implementation of a stepped-care system, primary-care offices will have to allocate group meeting room space. This space will also be useful for other behavioral group treatments that could be incorporated into the primary-care system such as pain management and weight-loss groups.

A stepped-care approach in a primary-care setting will help patients gain access to an effective and safe treatment for insomnia that might otherwise be inaccessible due to treatment barriers such as cost, lack of knowledge, and a limited supply of professionals trained in the delivery of CBT-I. The implementation of a stepped-care model in primary care could increase patient access to CBT-I, which could be especially beneficial to older adults who rely heavily on primary health clinics for their mental health needs. ${ }^{91}$ Since insomnia is more severe, prevalent, and associated with more health complications in older adults, ${ }^{92}$ increased access to CBT-I as a result of the implementation of a stepped-care model could be of particular benefit to older adults.

A stepped-care model has particular importance for individuals with insomnia that is comorbid with a physical disease or mental disorder (chronic pain, cancer, depression). Improvements in insomnia symptoms could have beneficial reciprocal effects for mental and physical health in addition to improving quality of life. Indeed, there is accumulating evidence that, CBT-I may have beneficial secondary outcomes for depression, anxiety, fatigue, and quality of life. ${ }^{58,93-95} \mathrm{~A}$ recent review concluded that CBT-I is associated with both improvements in sleep as well as medical and psychological symptoms. $^{38}$

The proposed stepped-care model for primary care is aspirational and would require several modifications to the current health care delivery system to be feasible. As a starting point, the larger primary-care practices that are part of health care reform will facilitate the hiring of behavioral specialists to provide preventive and behavioral treatment services. An additional major change would involve the insurance reimbursement structure for primary care, which would have to adapt to diversified treatment delivery modalities such as self-help programs and group therapy. Moreover, procedures will need to be established to enhance screening and patient tracking, necessary for the success of a steppedcare treatment model. ${ }^{42}$ Finally, additional sleep centers are needed in smaller communities that still do not have access to sleep centers.
This stepped-care approach for treating insomnia in primary care is relevant at a policy level because it supports the National Committee for Quality Assurance (NCQA) 2011 guidelines for how optimal comprehensive primary care will be structured in the future. The new NCQA guidelines for the Patient-Centered Medical Home Program (PCMH) endorse six standards for primary care, many of which are supported by the proposed stepped-care model (eg, extensive self-care instruction and ongoing assessment of outcomes). The guidelines also indicate that in order to be accredited as a patient-centered medical home (which will have reimbursement implications at the federal level), primary care clinics will have to demonstrate six "must-pass elements", one of which is to support the self-care process, a foundational principle of the stepped-care approach. ${ }^{96}$

\section{Discussion and future directions}

In order for the proposed stepped care model to be successfully implemented in a primary care setting, additional research is needed to provide further support and direction for some steps, and aspects of the steps, in the model.

Self-help CBT-I is an efficacious and accessible treatment alternative to therapist-led CBT-I, ${ }^{97,98}$ and can be delivered via manual, ${ }^{53,80,81}$ audiotape, ${ }^{99}$ videotape, ${ }^{54,100}$ and/or internet. ${ }^{82-84}$ The results of a meta-analysis on the efficacy of self-help CBT-I for insomnia demonstrated patients with insomnia benefit from self-help CBT-I treatment, but the effects of self-help treatments are small to moderate. ${ }^{98}$ Therefore, self-help treatments for insomnia are not intended to replace therapist-led interventions ${ }^{98}$ but could function well as a first step in a stepped-care program. There has been some preliminary evidence which supports the effectiveness of self-help treatments for insomnia delivered in primary-care settings, ${ }^{60,100,101}$ but there have yet to be any research studies specifically designed to determine self-help CBT-I effectiveness in primary-care settings. Therefore, the next step in the research literature should be an RCT to evaluate the effectiveness of self-help in a primary-care setting and thus provide evidence to support self-help as an effective first step in the stepped-care model proposed above.

Stepped-care models function on the principle that lower intensity interventions are to be attempted first, while more intensive treatments are reserved for those who do not respond to less intensive interventions. ${ }^{65}$ Although steppedcare models for the treatment of insomnia, ${ }^{42,78}$ including this one, propose steps of supposed differing intensity, there has been very little research conducted which compares the 
efficacy of CBT-I treatment delivered in various formats. As a result, there is not enough empirical evidence to say that individually administered CBT-I is significantly more effective than group-administered CBT-I, and that group CBT-I is more effective than self-help CBT-I. One exception is a study by Bastien and colleagues ${ }^{49}$ that directly compared different treatment formats (individual, group, or brief consultations over the phone). In this study, CBT-I did not lose its potency when delivered in a group format or delivered over the phone. However, once again, this treatment study involved self-referred participants rather than physicianreferred individuals in primary care.

The evidence is similarly limited when it comes to comparing the efficacy of self-help to therapist-administered CBT-I. Therapist-administered CBT-I is more effective than self-help according to comparisons of effect sized from metaanalyses. ${ }^{23,98}$ However, there has not been a study that directly compares these two types of treatment modalities.

In order to successfully implement a stepped-care model for insomnia treatment in primary care, it would be beneficial to identify patient factors that can be used to predict CBT-I treatment success for the less intensive treatments. ${ }^{55}$ A variety of prediction studies have been conducted showing that there are no contraindications to referring a patient for CBT-I, and treatment adherence ${ }^{58}$ has been the only factor identified thus far that predicts successful response to therapist-delivered CBT-I. ${ }^{102}$ That being said, a recent exploratory study by the authors sought to identify the predictors of treatment outcome in two previously published intervention studies for older adults with comorbid insomnia, one employing classroom CBT-I and the other using selfhelp CBT-I. ${ }^{103}$ The results extended previous findings of no contraindications for CBT-I by showing that the same held true for self-help treatment and by measuring a wider range of demographic, medical, or psychiatric variables than previously tested. One exception specific to self-help treatment was that individuals who held stronger beliefs about their dependency on sleep medications were less likely to benefit from treatment. ${ }^{104}$ This finding suggests that individuals who are highly dependent on sleep medications should likely bypass the first step of the proposed stepped-care model in favor of professionally guided CBT-I.

It is critical to identify patient factors such as these to predict treatment outcome so that empirically based decisions can be made regarding which patients should be referred to stepped-care insomnia treatment and at what level (step) they should start treatment. The identification of reliable predictors of treatment outcome could contribute to more efficient use of resources, increased treatment compliance, and greater patient satisfaction. ${ }^{102}$ Meanwhile, established predictors will also help identify people who would benefit from less expensive and less intensive self-help treatment.

A significant concern in this stepped-care approach is the possibility that patients who do not respond well to lower intensity treatments may be discouraged and unwilling to try a more intensive treatment. ${ }^{66}$ Treatment failure could reduce motivation ${ }^{76}$ or could negatively affect potential response to higher levels of treatment. ${ }^{70}$ Therefore, careful initial assessment of patients' insomnia severity and comorbid conditions is necessary to ensure the appropriate initial level of treatment is chosen. Additional empirically based factors should be used to determine appropriate level of care, such as level of self-efficacy or learning style. ${ }^{63}$ Patient preference can also be taken into consideration within specific steps where possible, such as allowing patients to choose between bibliotherapy, video-delivered therapy, or internet-delivered therapy.

Attrition at the initial levels of treatment could also be due to the fact that some individuals may not be ready to commit to significant behavioral changes to improve their sleep. The initial phase of CBT-I treatment was often described to patients as "sleep boot camp" or a "sleep diet" to emphasize the short-term challenges that are involved in the initial stages of sleep restriction. Additionally, many potential patients have had a favorable response to hypnotics, only to develop tolerance to those medications over a period of several months. Initially there is a hope that a new medication can be found that will not result in tolerance. The preference for an easy solution is human nature, and it takes trial and error experiences before patients are convinced that such solutions are not available.

A final and crucial point to emphasize is the need for a cadre of primary-care professionals to be trained in behavioral sleep medicine in order for stepped-care insomnia treatment to be effectively implemented in primary-care settings. Perlis and Smith ${ }^{52}$ argue that there are currently not enough behavioral sleep medicine trained therapists available to treat those patients who seek help. They make suggestions to address the issue of inadequate supply, which include offering a lesser certification to master's level clinicians and making cross-training opportunities available to those in nursing and social work fields. Perlis and $\mathrm{Smith}^{52}$ also call for increased training opportunities by encouraging informal mentorships and offering fellowships in behavioral sleep medicine.

The bottom line when considering the implications of stepped care in primary-care settings is early and effective treatment for insomnia could go a long way toward promoting 
health and conserving resources. ${ }^{22}$ Stepped care was developed in an effort to provide evidence-based treatments to a greater number of individuals at lower $\operatorname{cost}^{65}$ and therefore has the potential to reduce expenses for individuals and institutions as well as lower national health care costs. It has been established that CBT-I is a great product. It is effective, safe, and has enduring benefits shown to persist for at least 2 years. However, the product distribution system needs to be improved so that those who suffer from chronic insomnia can benefit from behavioral treatment. ${ }^{22}$ The implementation of a stepped-care approach to treating insomnia in a primary care setting is a promising solution to this significant public health problem.

\section{Disclosure}

The author reports no conflicts of interest in this work.

\section{References}

1. American Psychiatric Association: Diagnostic and Statistical Manual of Mental Disorders. 4th ed. Text revision. Washington, DC: American Psychiatric Association; 2000.

2. Drake CL, Roehrs T, Roth T. Insomnia causes, consequences, and therapeutics: an overview. Depress Anxiety. 2003;18:163-176.

3. Spielman AJ, Caruso LS, Glovinsky PB. A behavioral perspective on insomnia treatment. Psychiatr Clin North Am. 1987;10:541-553.

4. Edinger JD, Wohlgemuth WK, Radtke RA, Marsh GR, Quillian RE. Does cognitive-behavioral insomnia therapy alter dysfunctional beliefs about sleep? Sleep. 2001;24:591-599.

5. Perlis ML, Giles DE, Mendelson WB, Bootzin RR, Wyatt JK. Psychophysiological insomnia: the behavioural model and a neurocognitive perspective. J Sleep Res. 1997;6:179-188.

6. Ohayon M. Epidemiology of insomnia: what we know and what we still need to learn. Sleep Med Rev. 2002;6:97-102.

7. Morin CM, Bootzin RR, Buysse DJ, Edinger JD, Espie CA, Lichstein KL. Psychological and behavioral treatment of insomnia: update of the recent evidence (1998-2004). Sleep. 2006;29:1398-1414.

8. Ford DE, Kamerow DB. Epidemiologic study of sleep disturbances and psychiatric disorders. An opportunity for prevention? JAMA 1989;62:479-484.

9. Simon GE, VonKorff M. Prevalence, burden, and treatment of insomnia in primary care. Am J Psychiatry. 1997;154:1417-1423.

10. Walsh JK, Engelhardt CL. The direct economic costs of insomnia in the United States for 1995. Sleep. 1999;22(Suppl 2):S386-S393.

11. Stoller MK. Economic effects of insomnia. Clin Ther. 1994; 16:873-897.

12. Katz DA, McHorney CA. Clinical correlates of insomnia in patients with chronic illness. Arch Intern Med. 1998;158:1099-1107.

13. Breslau N, Roth T, Rosenthal L. Andreski P. Sleep disturbance and psychiatric disorders: a longitudinal epidemiological study of young adults. Biol Psychiatry. 1996;39:411-418.

14. Chang PP, Ford DE, Mead LA, Cooper-Patrick L. Insomnia in young men and subsequent depression. The Johns Hopkins Precursors Study. Am J Epidemiol. 1997;146:105-114.

15. Ancoli-Israel S. Sleep and aging: prevalence of disturbed sleep and treatment considerations in older adults. $J$ Clin Psychiatry. 2005;66:24-30.

16. Walsh JK. Clinical and socioeconomic correlates of insomnia. J Clin Psychiatry. 2004;65(Suppl 8):13-19.

17. Uchiyama M, Inoue $\mathrm{Y}$, Uchimura $\mathrm{N}$, et al. Clinical significance and management of insomnia. Sleep Biol Rhythms. 2011;9:63-72.
18. Walsh JK, Muehlbach MJ, Lauter SA, et al. Effects of triazolam on sleep, daytime sleepiness, and morning stiffness in patients with rheumatoid arthritis. J Rheumatol. 1996;23:245-252.

19. Stepanski E, Rybarczyk B. Emerging research on the treatment and etiology of secondary or comorbid insomnia. Sleep Med Rev. 2006;10:7-18.

20. National Institutes of Health. National Institutes of Health State of the Science Conference statement on manifestations and management of chronic insomnia in adults, June 13-15. Sleep. 2005;28:1049-1057.

21. Lichstein KL. Secondary insomnia. In: Lichstein KL, Morin CM, editors. Treatment of Late-life Insomnia. Thousand Oaks, CA: Sage; 2000:297-319.

22. Edinger JD, Sampson WS. A primary care "friendly" cognitive behavioral insomnia therapy. Sleep. 2003;26:177-182.

23. Smith MT, Perlis ML, Park A, et al. Comparative meta-analysis of pharmacotherapy and behavior therapy for persistent insomnia. Am J Psychiatry. 2002;159:5-11.

24. Morin CM, Hauri PJ, Espie CA, Spielman AJ, Buysse DJ, Bootzin RR. Nonpharmacologic treatment of chronic insomnia. An American Academy of Sleep Medicine review. Sleep. 1999;22:1134-1156.

25. Kripke DF. Chronic hypnotic use: deadly risks, doubtful benefit. Sleep Med Rev. 2000;4:5-20.

26. Riemann D, Perlis ML. The treatments of chronic insomnia: a review of benzodiazepine receptor agonists and psychological and behavioral therapies. Sleep Med Rev. 2009;13:205-214.

27. Kripke DF, Klauber MR, Wingard DL, et al. Mortality hazard associated with prescription hypnotics. Biol Psychiatry. 1998;43:687-693.

28. Morin CM, Wooten V. Psychological and pharmacological approaches to treating insomnia: critical issues in assessing their separate and combined effects. Clin Psychol Rev. 1996;16:521-542.

29. Nelson J, Chouinard G. Canadian Society for Clinical Pharmacology. Guidelines for the clinical use of benzodiazepines: pharmacokinetics, dependency, rebound and withdrawal. Can J Clin Pharmacol. 1999;6:69-83.

30. Glass J, Lanctot KL, Herrmann N, Sproule BA, Busto UE. Sedative hypnotics in older people with insomnia: meta-analysis of risks and benefits. BMJ. 2005;331:1169-1175.

31. Mendelson WB. A review of the evidence for the efficacy and safety of trazodone in insomnia. Clin Psychiatry. 2005;66:469-476.

32. Bootzin RR, Nicassio PM. Behavioral treatments for insomnia. In: Hersen M, Eisler R, Miller P, editors. Progress in Behavior Modification. New York: Academic Press; 1978:1-45.

33. Spielman AJ, Saskin P, Thorpy, MJ. Treatment of chronic insomnia by restriction of time in bed. Sleep. 1987;10:45-56.

34. Morin CM. Insomnia: Psychological Assessment and Management. New York: Guilford; 1993.

35. Petit L, Azad N, Byszewski A, Sarazan F, Power B. Non-pharmacological management of primary and secondary insomnia among older people: review of assessment tools and treatments. Age Ageing. 2003;32:19-25.

36. Friedman L, Bliwise DL, Yesavage JA, Salom SR. A preliminary study comparing sleep restriction and relaxation treatments for insomnia in older adults. J Gerontol. 1991;46:1-8.

37. Espie CA, Lindsay WR, Brooks DN, Hood EM, Turvey T. A controlled comparative investigation of psychological treatments for chronic sleep-onset insomnia. Behav Res Ther. 1989;27:79-88.

38. Smith MT, Huang MI, Manber R. Cognitive behavior therapy for chronic insomnia occurring within the context of medical and psychiatric disorders. Clin Psychol Rev. 2005;25:559-592.

39. Morin CM, Culbert JP, Schwartz SM. Nonpharmacological interventions for insomnia: a meta-analysis of treatment efficacy. Am J Psychiatry. 1994;151(8):1172-1180.

40. Edinger JD, Wohlgemuth WK, Radtke RA, Coffman CJ, Carney CE. Dose-response effects of cognitive-behavioral insomnia therapy: a randomized clinical trial. Sleep. 2007;30:203-212.

41. Morin CM, Colecchi CA, Stone J. Sood R, Brink D. Behavioral and pharmacological therapies for late-life insomnia: a randomized clinical trial. JAMA. 1999;281:991-999. 
42. Espie CA. Stepped care: a health technology solution for delivering cognitive behavioral therapy as a first line of insomnia treatment. Sleep. 2009;32:1549-1558.

43. Rybarczyk B, Stepanski E, Fogg L, Lopez M, Barry P, Davis A. A Placebo-controlled test of CBT for comorbid insomnia in older adults. J Consult Clin Psychol. 2005;73:1164-1174.

44. Irwin MR, Cole JC, Nicassio PM. Comparative meta-analysis of behavioral interventions for insomnia and their efficacy in middle-aged adults and in older adults 55+ years of age. Health Psychol. 2006;25:3-14.

45. Sivertsen B, Omvik S, Pallesen S, et al. Cognitive behavioral therapy vs zopiclone for treatment of chronic primary insomnia in older adults: a randomized controlled trial. JAMA. 2006;295:2851-2858.

46. Jacobs GD, Pace-Schott EF, Stickgold R, Otto MW. Cognitive behavior therapy and pharmacotherapy for insomnia: a randomized controlled trial and direct comparison. Arch Intern Med. 2004;164:1888-1896.

47. Morin C, Gaulier B, Barry T, Kowatch R. Patients' acceptance of psychological and pharmacological therapies for insomnia. Sleep. 1992; 15:302-305.

48. Ancoli-Israel S, Roth T. Characteristics of insomnia in the United States: results of the 1991 National Sleep Foundation Survey. Sleep. 1999;22(Suppl 2):S347-S353.

49. Bastien CH, Morin CM, Ouellet MC, Blais FC, Bouchard B. cognitivebehavioral therapy for insomnia: comparison of individual therapy, group therapy, and telephone consultations. J Consult Clin Psychol. 2004;72:653-659.

50. Nowell PD, Mazumdar S, Buysse DJ, Dew MA, Reynolds CF, Kupfer DJ. Benzodiazepines and Zolpidem for chronic insomnia. JAMA. 1997;278:2170-2177.

51. Perlis ML, Smith MT, Cacialli DO, Nowkowski S, Orff H. On the comparability of pharmacotherapy and behavior therapy for chronic insomnia. commentary and implications. J Psychosom Res. 2003;54:51-59.

52. Perlis ML, Smith MT. How can we make CBT-I and other BSM services widely available? J Clin Sleep Med. 2008;4:11-13.

53. Alperson J, Biglan A. Self-administered treatment of sleep onset insomnia and the importance of age. Behav Ther. 1979;10:347-356.

54. Riedel BW, Lichstein KL, Dwyer WO. Sleep compression and sleep education for older insomniacs: self-help versus therapist guidance. Psychol Aging. 1995;10;54-63.

55. Edinger JD. Is it time to step up to stepped care with our cognitivebehavioral insomnia therapies? Sleep. 2009;32:1549-1558.

56. Baillargeon L, Demers M. Ladouceur R. Stimulus-control: nonpharmacologic treatment for insomnia. Can Fam Physician. 1998; 44:73-79.

57. Hajak G, Bandelow B, Zulley J, Pittrow D. "As needed" pharmacotherapy combined with stimulus control treatment in chronic insomnia - assessment of a novel intervention strategy in a primary care setting. Ann Clin Psychiatry. 2002;14:1-7.

58. Espie CA, MacMahon KMA, Kelly H, et al. Randomized clinical effectiveness trial of nurse-administered small-group cognitive behavior therapy for persistent insomnia in general practice. Sleep. 2007;30:574-584.

59. Espie CA, Inglis, SJ, Tessier S, Harvey L. The clinical effectiveness of cognitive behaviour therapy for chronic insomnia: implementation and evaluation of a sleep clinic in general medical practice. Behav Res Ther. 2001;39:45-60.

60. Goodie JL, Isler WC, Hunter C, Peterson AL. Using behavioral health consultants to treat insomnia in primary care: a clinical case series. J Consult Clin Psychol. 2009;65:294-304.

61. Edinger JD, Wohlgemuth WK, Radtke RA, Marsh GR, Quillian RE. Cognitive behavioral therapy for treatment of chronic primary insomnia: a randomized controlled trial. JAMA. 2001;285:1856-1864.

62. Jacobs GD. Say Good Night to Insomnia: the 6-week solution. New York: Henry Holt; 1998.

63. Williams C, Martinez R. Increasing access to CBT: stepped care and CBT self-help models in practice. Behav Cogn Psychother. 2008;36:675-683.
64. Kessler RC, McGonagle KA, Zhao S, et al. Lifetime and 12-month prevalence of DSM-III-R psychiatric disorders in the United States: results from the national comorbidity study. Arch Gen Psychiatry. 1994;51:8-19.

65. Haaga DF. Introduction to the special section on stepped care models in psychotherapy. J Consult Clin Psychol. 2000;68:547-548.

66. Scogin FR, Hanson A, Welsh D. Self-administered treatment in stepped-care models of depression treatment. J Clin Psychol. 2003;59:341-349.

67. Gjerdingen D, Katon W, Rich DE. Stepped care treatment of postpartum depression: a primary care-based management model. Women. 2008;18:44-52.

68. Newman MG. Recommendations for a cost-offset model of psychotherapy allocation using generalized anxiety disorder as an example. J Consult Clin Psychol. 2000;63:549-555.

69. Salloum A. Minimal therapist-assisted cognitive-behavioral therapy interventions in stepped care for childhood anxiety. Prof Psychol Res Pr. 2010;41:41-47.

70. Wilson GT, Vitousek KM, Loeb KL. Stepped care treatment for eating disorders. Arch Gen Psychiatry. 2000;68:564-572.

71. Sobell MB, Sobell LC. Stepped care as a heuristic approach to the treatment of alcohol problems. J Consult Clin Psychol. 2000;68:573-579.

72. Tolin DF, Diefenbach GJ, Maltby N, Hannan S. Stepped care for obsessive-compulsive disorder: a pilot study. Cogn Behav Pract. $2005 ; 12: 403-414$

73. National Collaborating Center for Mental Health. The treatment and management of depression in adults. NICE clinical guideline 90. National Institute for Health and Clinical Excellence; 2009.

74. National Collaborating Center for Mental Health and National Collaborating Center for Primary Care. Generalised anxiety disorder and panic disorder (with or without agoraphobia) in adults. Management in primary, secondary and community care. NICE clinical guideline 113. National Institute for Health and Clinical Excellence; 2011.

75. Katon WK, Von Korff M, Lin E, et al. Stepped collaborative care for primary care patients with persistent symptoms of depression: a randomized trial. Arch Gen Psychiatry. 1999;56:1109-1115.

76. Davison GC. Stepped care: doing more with less? Arch Gen Psychiatry. 2000;68:580-585

77. Berner M, Günzler C, Frick K, et al. Finding the ideal place for a psychotherapeutic intervention in a stepped care approach - a brief overview of the literature and preliminary results from the project predict. Int $J$ Methods Psychiatr Res. 2008;17(Suppl 1):S60-S64.

78. Edinger JD, Carney CE. Behavioral treatment of insomnia. In: Kushida CA, editor. Handbook of Sleep Disorders. New York: Informa Healthcare; 2008:71-90.

79. Oosterhuis A, Klip E. The treatment of insomnia through mass media, the results of a televised behavioral training programme. Soc Sci Med. 1997;45:1223-1229.

80. Mimeault V, Morin CM. Self-help treatment for insomnia: bibliotherapy with and without professional guidance. J Consult Clin Psychol. 1999;67:511-519.

81. Morin CM, Beaulieu-Bonneau S, LeBlanc M, Savard J. Self-help treatment for insomnia: a randomized controlled trial. Sleep. 2005;28: 1319-1327.

82. Ström L, Pettersson R, Andersson G. Internet-based treatment for insomnia: a controlled evaluation. J Consult Clin Psychol. 2004;72:113-120.

83. Ritterband LM, Thorndike FP, Gonder-Frederick LA, et al. Efficacy of an Internet-based behavioral intervention for adults with insomnia. Arch Gen Psychiatry. 2009;66:692-698.

84. Vincent N, Lewycky S. Logging on for better sleep: RCT of the effectiveness of online treatment for insomnia. Sleep. 2009;32:807-815.

85. National Institute of Mental Health. Translating behavioral science into action: report of the National Advisory Mental Council Behavioral Science Workgroup. July 6, 2000. Available from: http://www.nimh. nih.gov/council/bswsummary.cfm. 
86. McDaniel SH, Fogarty CT. What primary care psychology has to offer the patient-centered medical home. Prof Psychol Res Pr. 2009; 40:483-492.

87. Blais FC, Morin MC, Boisclair A, Grenier V, Guay B. Can Fam Physician. 2001;47:759.

88. Morphy H, Dunn KM, Lewis M, Boardman HF, Croft PR. Epidemiology of insomnia: A longitudinal study in a UK population. Sleep. 2007; $30: 274-280$.

89. Buenaver LF, McGuire L, Haythornthwaite JA. Cognitive-Behavioral self-help for chronic pain. J Clin Psychol. 2006;62:1389-1396.

90. Morin CM, Vallires A, Guay B, et al. Cognitive behavioral therapy, singly and combined with medication, for persistent insomnia: a randomized controlled trial. JAMA. 2009;301:2005-2015.

91. Kaplan MS, Adamek ME, Calderon A. Managing depressed and suicidal geriatric patients: differences among primary care physicians. Gerontologist. 1999;39:417-425.

92. Lichstein KL. Secondary insomnia. In Lichstein KL, Morin CM, editors. Treatment of Late-life Insomnia. Thousand Oaks, CA: Sage; 2000: 297-319.

93. Quesnel C, Savard J, Simard S, Ivers H, Morin CM. Efficacy of cognitive-behavioral therapy for insomnia in women treated for nonmetastatic breast cancer. J Consult Clin Psychol. 2003;71(1):189-200.

94. Dirksen SR, Epstein DR. Efficacy of an insomnia intervention on fatigue, mood and quality of life in breast cancer survivors. JAdv Nurs. 2008;61:664-675.

95. Manber R, Edinger JD, Gress JL, San Pedro-Salcedo MG, Kuo TF, Kalista T. Cognitive behavioral therapy for insomnia enhances depression outcome in patients with comorbid major depressive disorder and insomnia. Sleep. 2008;31:489-495.

96. National Committee for Quality Assurance (NCQA) 2011 guidelines [homepage on the Internet] NCQA's Patient-Centered Medical Home (PCMH) 2011. Available at: http://www.ncqa.org/tabid/631/default. aspx. Accessed May 17, 2011.
97. Rybarczyk BD, Mack LJ. Self-help treatments for older adults with primary and comorbid insomnia. In Pandi-Perumal SR, Monti JM, Monjan AA, editors. Principles and Practice of Geriatric Sleep Medicine. Cambridge, UK: Cambridge University Press; 2009.

98. van Straten A, Cuijpers P. Self-help therapy for insomnia: A metaanalysis. Sleep Med Rev. 2009;13:61-71.

99. Morawetz D. Behavioral self-help treatment for insomnia: A controlled evaluation. Behav Ther. 1989;20:365-379

100. Rybarczyk B, Lopez M, Schelble K, Stepanski E. Home-based video CBT for comorbid geriatric insomnia: A pilot study using secondary data analyses. Behav Sleep Med. 2005;3:158-175.

101. Rybarczyk B, Lopez M, Benson R, Stepanski E. Efficacy of two behavioral treatment programs for comorbid geriatric insomnia. Psychol Aging. 2002;17:288-298.

102. Gagné A, Morin CM. Predicting treatment response in older adults with insomnia. J Clin Geropsychol. 2001,7:131-143.

103. Rybarczyk BD, Mack LJ, Lund HG, Alsten CR. Testing Two Self-Help CBT Interventions for Primary and Comorbid Insomnia in Older Adults. Poster presented at the Annual Meeting of the Society of Behavioral Medicine, Montreal, QC, Canada. April, 2009.

104. Mack LJ, Rybarczyk BD. Predicting Treatment Response to Cognitive Behavioral Therapy in Adults with Comorbid Insomnia. Poster presented at the Annual Meeting of the Society of Behavioral Medicine, Washington, DC. April, 2011.

105. McClusky HY, Milby JB, Switzer PK, Williams PK, Wooten V. Efficacy of behavioral versus triazolam treatment in persistent sleep-onset insomnia. Am J Psychiatry. 1991;148:121-126.

106. Wu R, Bao 1, Zhang C, Deng J, Long C. Comparison of sleep condition and sleep-related physiological activity after cognitive-behavior and pharmacological therapy for chronic insomnia. Psychother Psychosom. 2006; 75:220-228.
Nature and Science of Sleep

\section{Publish your work in this journal}

Nature and Science of Sleep is an international, peer-reviewed, open access journal covering all aspects of sleep science and sleep medicine, including the neurophysiology and functions of sleep, the genetics of sleep, sleep and society, biological rhythms, dreaming, sleep disorders and therapy, and strategies to optimize healthy sleep. The journal welcomes

\section{Dovepress}

original research, clinical \& epidemiological studies, reviews \& evaluations, case reports and extended reports. The manuscript management system is completely online and includes a very quick and fair peerreview system, which is all easy to use. Visit http://www.dovepress.com/ testimonials.php to read real quotes from published authors. 